\title{
A novel thermoplastic elastomer based on dynamically vulcanized polypropylene/acrylic rubber blends
}

\author{
B. G. Soares ${ }^{1 *}$, D. M. Santos ${ }^{1}$, A. S. Sirqueira ${ }^{2}$ \\ ${ }^{1}$ Instituto de Macromoléculas, Universidade Federal do Rio de Janeiro, Centro de Tecnologia, Bloco J, Ilha do Fundão, \\ 21945-970, Rio de Janeiro, RJ, P.O.Box 68525, Brazil \\ ${ }^{2}$ Universidade Estadual da Zona Oeste, Rio de Janeiro, RJ, Brazil
}

Received 30 April 2008; accepted in revised form 10 July 2008

\begin{abstract}
Thermoplastic elastomer based on polypropylene (PP) and acrylic rubber (ACM) was investigated, with special attention on the compatibilization and dynamic vulcanization. ACM component contains chlorine and carboxyl groups along the backbone, which act as center for the curing and reactive compatibilization. The last event was carried out by adding a combination of maleic anhydride-modified PP (PP-g-MA) and triethylene tetramine (TETA), which act as interfacial agents between PP and ACM phases. The effectiveness of the compatibilization was suggested from mixing torque and viscosity, determined from rheological measurements. Outstanding mechanical performance, especially elongation at break, and better tensile set (lower values) were obtained with the compatibilization. The dynamic vulcanization also resulted in good mechanical properties for compatibilized blends, but the performance was inferior to that observed for non vulcanized blends. The effect of the compatibilization and/or dynamic vulcanization on the dynamic mechanical, thermal, morphological and stress relaxation properties was investigated.
\end{abstract}

Keywords: polymer blends and alloys, acrylic rubber, TPV, reactive compatibilization, dynamic vulcanization

\section{Introduction}

Polyacrylates (ACM) are oil resistant and high temperature resistant rubbers, which find important applications as oil seals and gaskets used in high performance auto engines [1]. Blending this rubber with a thermoplastic is a good approach for the development of oil resistant and processable materials. ACM is a saturated rubber and it is commercialized with different types of cure-site monomers $[2,3]$. These sites can react with functional groups present in other polymers during the melt processing, producing graft copolymers or networks at the interface, which act as bridges between the phases. This process, known as reactive compatibilization, decreases the interfacial tension and increases the interfacial adhesion. Consequently a fine morphol- ogy is usually achieved for these blends, which contributes to an improvement of the overall properties. Some few examples of ACM - based elastomer thermoplastics are reported in the literature and include blends with nylon [4-7], poly(vinyl chloride) (PVC) [8, 9], poly(vinylidene fluoride) (PVDF) [10], poly (ethylene terephthalate) [11] and chlorinated polypropylene [12]. In all these blends, the thermoplastic component is polar, and presents some affinity with the ACM rubber. In the case of nylon or PET/ACM blends, the presence of the epoxide as the cure site monomer in the ACM backbone also provides an effective anchorage between the phases through the reaction between the epoxide groups of ACM and amino or carboxyl groups of nylon and PET, respectively $[4,11]$. 
Another important method to improve the elastomeric properties and processability of the thermoplastics is the dynamic vulcanization of the rubber phase in the presence of a suitable crosslinking agent, during the melt mixing with the thermoplastics, giving rise to a thermoplastic vulcanizate (TPV) [13]. This technique has been employed in the development of several TPVs. Most of them are constituted by polypropylene as the thermoplastic component and different vulcanized rubbers dispersed in the polypropylene matrix, such as ethylene-propylene-diene rubber (EPDM) [14-16], nitrile rubber [17-21] and natural rubber [22, 23], among others. However, to the best of our knowledge, there is no report in the accessible literature dealing with blends constituted by polypropylene and acrylic rubber.

Therefore, the aim of the present work is to investigate the performance of ACM as the rubber component in polypropylene- based thermoplastic elastomer blends. Because of the high incompatibility between the components, a technological compatibilization is necessary in order to improve the mechanical performance for commercial uses. The ACM grade used in this work was produced by Petroflex Ind. Com S.A. in Brazil, and contains double active cure-sites based on chlorine and carboxyl groups. Such functional groups can react with an appropriate functionalized polypropylene to promote a reactive compatibilization. This work evaluates the efficiency of maleic anhydridegrafted polypropylene (PP-g-MA) in combination with triethylenetetramine (TETA) as the reactive compatibilizer system for the PP/ACM blends. Fig- ure 1 illustrates the possible reactions that should take place at the interface of these blends, during the melt processing. The effect of the reactive compatibilization and dynamic vulcanization on the mechanical, dynamic mechanical, rheological and morphological properties as well as stress relaxation behavior of PP/ACM blends was discussed in detail.

\section{Experimental}

\subsection{Materials}

Acrylic rubber, Hicryl 1540, (ACM), [derived from the polymerization of ethyl acrylate and containing carboxyl and chlorine as the double cure site groups; Mooney viscosity $\left(\mathrm{ML} 1+4\right.$ at $\left.100^{\circ} \mathrm{C}\right)=40$ ] were kindly supplied by Petroflex Ind. Com. S.A. Rio de Janeiro, Brazil. Polypropylene (melt flow index $=3.5 \mathrm{~g} / 10 \mathrm{~min}$ at $230^{\circ} \mathrm{C} / 2.16 \mathrm{~kg}$ ) was supplied by Braskem S.A., Rio Grande do Sul, Brazil. Maleic anhydride-modified polypropylene (PP-gMA) (Polybond 3200) (melt flow index = $115 \mathrm{~g} / 10 \mathrm{~min}$ at $190^{\circ} \mathrm{C} / 2.16 \mathrm{~kg} ; 1 \mathrm{wt} \%$ of maleic anhydride) was purchased by Crompton, Middlebury, CT, USA. Triethylene-tetramine (TETA), stearic acid and sodium stearate was purchased by Vetec Ind Quimicas, Rio de Janeiro, Brazil. WB-222, a processing agent based on aliphatic fatty acid esters, used for the ACM, was supplied by Struktol (Stow, Ohio, USA). Naphtenic oil is a mineral insulating oil produced by Petrobrás, Rio de Janeiro, Brazil. Chemac Park 50, a hexamethylenediamine carbamate, was supplied by Chemicon Ind. Quim. S.A., (São Paulo, Brazil).

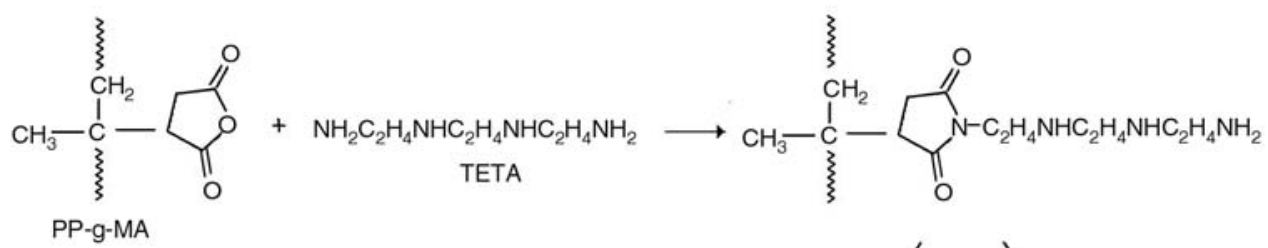

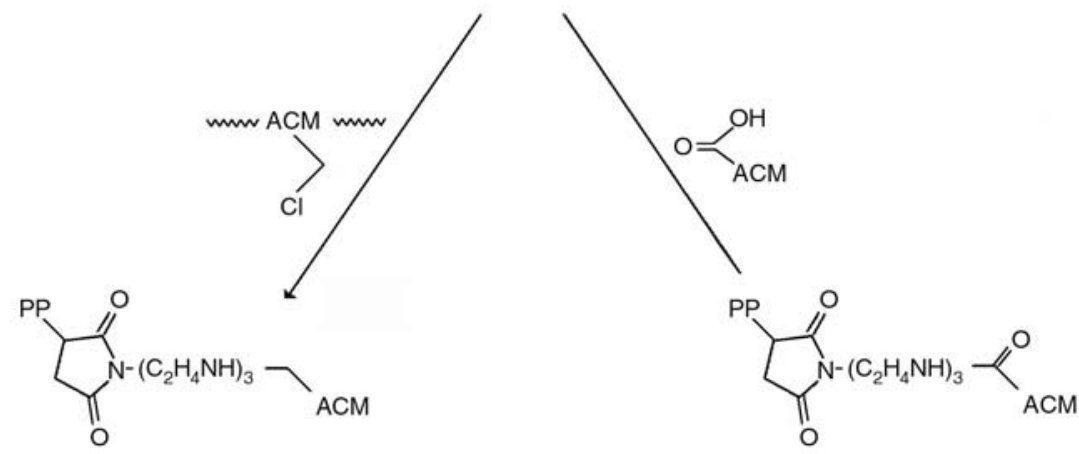

Figure 1. Possible reactions that occur at the interface of the compatibilized PP/ACM blends 


\subsection{Blend preparation}

The blends were prepared in an internal Brabender plasticorder mixer (supplier), with banbury type rotors at $80 \mathrm{rpm}$ at a mixer set point temperature of $185^{\circ} \mathrm{C}$. PP was first charged and melted for $2 \mathrm{~min}$ in the chamber. Then, ACM was added and processed for $3 \mathrm{~min}$, followed by the addition of naphtenic oil as the plasticizer. The mixing was continued for $7 \mathrm{~min}$. In the case of compatibilized blends, PP-g-MA was added together with PP and TETA was added after the ACM addition and processed for $2 \mathrm{~min}$. Then, the naphtenic oil was added and mixing was continued for $7 \mathrm{~min}$.

For dynamically vulcanized blends, WB-222 and stearic acid were used as the processing aids. After the introduction of PP/PP-g-MA/ACM/TETA in this order, the processing aids (WB-222/stearic acid) were added. Two min later, sodium stearate was added and the mixture continued for $2 \mathrm{~min}$, followed by the addition of Chemac Park 50, which was processed for an additional $3 \mathrm{~min}$. The resultant blends were then discharged from the internal mixer in the form of lumps. The cooled lumps were milled and injection molded at $240^{\circ} \mathrm{C}$ with a pressure of 300 bar, in a Haake miniJet.

\subsection{Physical testing}

Tensile testing was done following the ASTM D638-5 method using dumb bell shaped samples at a cross-head speed of $100 \mathrm{~mm} / \mathrm{min}$ with an Instron 5569 universal testing machine (Boston, MA, USA). Five specimens were used and the average was calculated in each case.

For the compression set test, cylindrical test specimens $(12.5 \mathrm{~mm}$ diameter and $6.0 \mathrm{~mm}$ thickness) were injected at $240^{\circ} \mathrm{C}$. The tests were done by pressing the specimens to $25 \%$ of their original thickness, according to ASTM D395-85 and aged in an air oven of controlled ventilation at $100^{\circ} \mathrm{C}$ for $22 \mathrm{~h}$ before determining their thickness recovery upon release of the compressive force.

Tension set and stress relaxation experiments were also performed in a Universal testing machine (Instron 5569). For tensile set experiments, the specimens were elongated until 50 or $100 \%$ of deformation at the rate of $100 \mathrm{~mm} / \mathrm{min}$ and $25^{\circ} \mathrm{C}$ and kept at that position for $10 \mathrm{~min}$. It was relaxed back to unstressed condition and equilibrated for $24 \mathrm{~h}$. The percentage of change in the length of the sample before and after extension was taken as tension set. For the blends that did not exceed 50 or $100 \%$ elongation, tension set at break was reported. Stress relaxation experiments were carried out in a Universal testing machine (Instron 5569). The dumb bell shaped specimens were pulled to the $100 \%$ elongation at a strain rate of $100 \mathrm{~mm} / \mathrm{min}$ and the decay in stress as a function of time was recorded.

\subsection{Oil resistance}

The oil resistance of the samples was determined by immersing the specimens in ASTM \#3 oil at $100^{\circ} \mathrm{C}$ for $22 \mathrm{~h}$, as per ASTM D471-98.

\subsection{Dynamic mechanical analysis}

The dynamic mechanical analyses of the blends were obtained by using the DMA analyzer (Q800; TA Scientific, New Castle, DE). The sample specimens were analyzed in single cantilever mode at a constant frequency of $1 \mathrm{~Hz}$, strain amplitude of $30 \mu \mathrm{m}$ and temperature ranging from -50 to $+40^{\circ} \mathrm{C}$, with a heating rate of $2^{\circ} \mathrm{C} / \mathrm{min}$. The temperature corresponding to the peak in $\tan \delta$ versus temperature plot was taken as the glass-to-rubber transition temperature $\left(T_{g}\right)$.

\subsection{DSC analysis}

The melting and crystallization behaviors of PP/ACM blends were determined using a PerkinElmer DSC-7 apparatus. The samples were heated at a rate of $10^{\circ} \mathrm{C} / \mathrm{min}$ from 40 to $200^{\circ} \mathrm{C}$ and annealed at $200^{\circ} \mathrm{C}$ for $5 \mathrm{~min}$, in order to remove any crystalline nuclei. The samples were then cooled to $40^{\circ} \mathrm{C}$ at a rate of $10^{\circ} \mathrm{C} / \mathrm{min}$ and heated again to $200^{\circ} \mathrm{C}$ at a rate of $10^{\circ} \mathrm{C} / \mathrm{min}$.

\subsection{Scanning electron microscopy}

Scanning electron microscopy (SEM) was performed on a JEOL 5610 LV equipment (Tokyo, Japan) using backscattered electron detector and a voltage of $15 \mathrm{kV}$. The samples were cryo-fractured and the surface was treated with ruthenium tetroxide $\left(\mathrm{RuO}_{4}\right)$ for $5 \mathrm{~min}$ in order to selectively stain the acrylic rubber phase. The samples were then coated with a thin layer of carbon and observed by SEM. 


\subsection{Rheological properties}

Rheological characterization of the systems was carried out using an Anton Paar Physica MCR301 rheometer (Graz, Austria) disposed with parallelplates with a diameter of $25 \mathrm{~mm}$. The measurements were done at $220^{\circ} \mathrm{C}$. For strain sweep measurements, it was used a strain range of $10^{-2}$ to $300 \%$ and an angle frequency of $7.5 \mathrm{rad} / \mathrm{s}$. The measurements with frequency sweep were done at a constant strain of $2.5 \%$ and a frequency range of 0.1 to $100 \mathrm{rad} / \mathrm{s}$.

\section{Results and discussion}

\subsection{The Effect of the Compatibilization}

\subsubsection{Brabender data}

The effect of PP-g-MA/TETA compatibilizing system was first investigated in non vulcanized PP/ACM (50:50 parts) blends. Figure 2 shows the actual temperature versus time plots for the blends as a function of the compatibilization. The amount of PP-g-MA was fixed as 5\% and the TETA, used as the coupling agent, was varied. All blends exhibited an increase of the internal temperature in the mixer, which were higher than the setting temperature. This is due to the viscous heating of the polymers during the processing. For compatibilized blends (curves B and C), the actual temperature in the mixer reached $200^{\circ} \mathrm{C}$, due to both viscous heating of the highly viscous network formed by the reaction between the functional groups and also

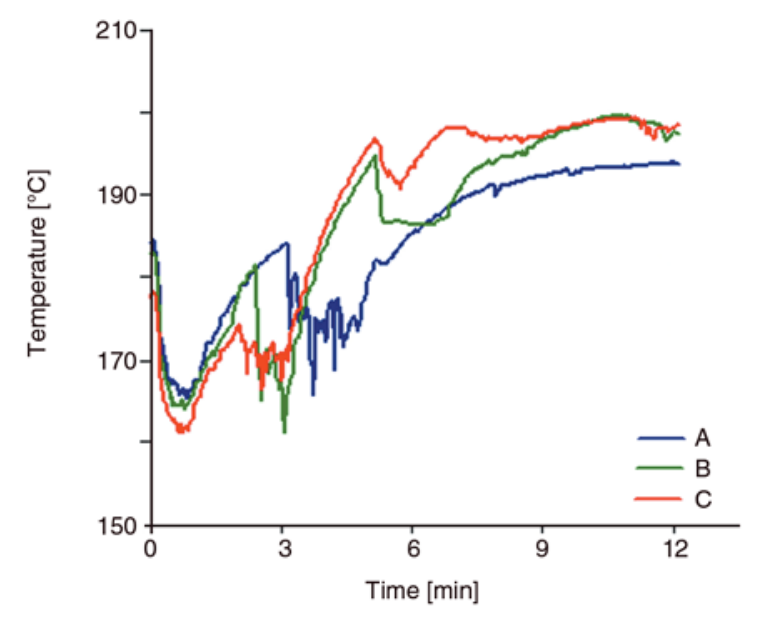

Figure 2. Dependence of the actual temperature with the time for non vulcanized PP/ACM (50:50 parts) blends, as a function of the compatibilization. (A) non compatibilized blend; and compatibilized blend with $5 \%$ of PP-g-MA and (B) $0.2 \%$ of TETA or (C) $0.5 \%$ TETA. due to the exothermic heat of the chemical reactions.

The variation of the torque during time blending also gives information regarding the extent of the reaction which occurs during the reactive compatibilization of a blend in the melt. Figure 3 shows the torque versus time plots for these blends as a function of the compatibilization. The first increase in torque was related to the PP feed torque. At this stage, the torque level was lower for compatibilized blends because of the presence of the PP-g-MA (which has a lower viscosity compared to pure PP). After the ACM addition, the torque level increased and this effect was more pronounced in compatibilized blends because of the interactions between the ACM and PP-g-MA. The torque decreased with the addition of TETA (point a) because of the introduction of the low molecular weight component, but immediately increased and reached a plateau higher than that of non compatibilized blend as a consequence of the chemical reactions between the functional groups of ACM and PP-g-MA with TETA, as illustrated in Figure 1. The addition of higher amount of TETA (curve C) contributed to an additional increase of torque probably because of the higher amount of crosslinked material formed at the interface, giving rise to a more viscous system. After the addition of the plasticizer (point $b$ ) the torque leveled off and stabilized in a higher level than that of non compatibilized blend. These results confirm the reactive compatibilization of these blends during melting.

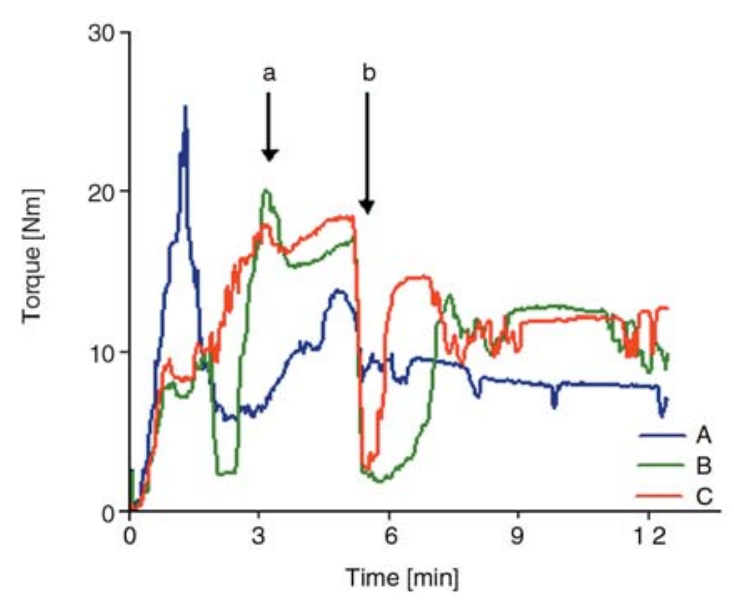

Figure 3. Dependence of the torque with time for non vulcanized PP/ACM (50:50 parts) blends, as a function of the compatibilization. (A) non compatibilized blend; and compatibilized blend with $5 \%$ of PP-g-MA and (B) $0.2 \%$ of TETA or (C) $0.5 \%$ TETA. 


\subsubsection{Rheological studies}

The reactive compatibilization was also evidenced from rheological experiments. Figure 4 illustrates the dependence of the storage modulus $\left(G^{\prime}\right)$ with the frequency for non compatibilized and compatibilized PP/ACM blends. The compatibilizing blends displayed higher storage modulus, confirming the presence of entanglements at the interface as a consequence of the reactive compatibilization. Blend containing $0.5 \%$ of TETA (curve C) presented lower values of $G^{\prime}$, probably because of the lubricating effect of this coupling agent, TETA, which competes with the network formation at the interface. The compatibilization also resulted in a substantial increase of the viscosity, as illustrated in Figure 5. At low deformation, the viscosity of the blend containing $0.5 \%$ of TETA was lower than that one containing $0.2 \%$ TETA, because of the lubricating effect of the TETA. However, at higher deformation, the viscosity of the blend containing higher amount of TETA was higher because of the formation of junction points at the interface in a higher extent.

The possible reactions which occur during processing of the compatibilized blends are illustrated in Figure 1. The use of PP-g-MA needs the presence of TETA to promote the coupling reaction. The amino groups of TETA react with the anhydride groups of the PP-g-MA forming the imide group. The other amino groups in this new functionalized PP may react with both carboxyl groups and chlorine groups located on the ACM backbone. These reactions give rise to a network at the interface, which is responsible for the increase of torque and viscosity of the blend.

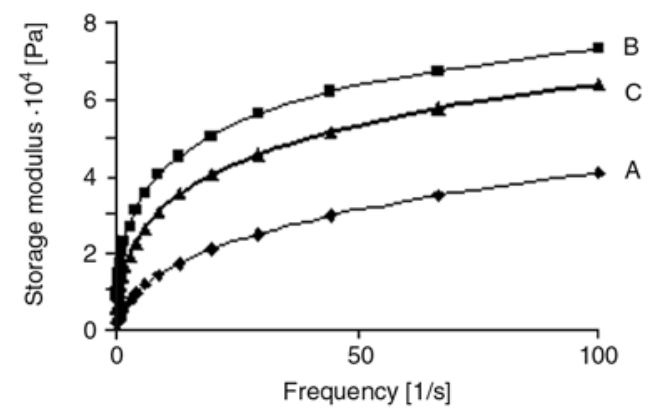

Figure 4. Dependence of storage modulus $\left(G^{\prime}\right)$ with frequency for non vulcanized PP/ACM (50:50 parts) blends, as a function of the compatibilization. (A) non compatibilized blend; compatibilized blend with $5 \%$ of PP-g-MA and (B) $0.2 \%$ of TETA or (C) $0.5 \%$ TETA.

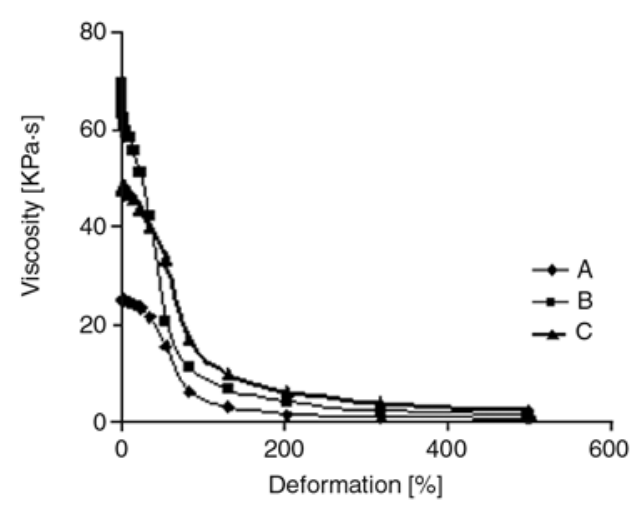

Figure 5. Dependence of viscosity with deformation for non vulcanized PP/ACM (50:50 parts) blends, as a function of the compatibilization. (A) non compatibilized blend; and compatibilized blend with $5 \%$ of PP-g-MA and (B) $0.2 \%$ of TETA or (C) $0.5 \%$ TETA.

\subsubsection{Physical and mechanical properties}

Table 1 summarizes the physical and tensile properties of non vulcanized PP/ACM (50:50 parts) blends. The compatibilization resulted in a significant improvement of tensile properties, especially the elongation at break. The oil resistance was also improved with the compatibilization. Compatibilized blends also exhibited superior tension set at 50 and $100 \%$ elongation, that is, lower tension set value. The tension set of non compatibilized blend could not be determined at $100 \%$ elongation because failures of specimen occurred at elongation

Table 1. Physical and mechanical properties of non vulcanized PP/ACM blends

\begin{tabular}{|l|c|c|c|}
\hline \multicolumn{1}{|c|}{ Ingredients (by weight) } & NV1 & NV2 & NV3 \\
\hline PP & 50 & 45 & 45 \\
\hline ACM & 50 & 50 & 50 \\
\hline PP9g-MA & 0 & 5 & 5 \\
\hline TETA & 10 & 10 & 10 \\
\hline Naphtenic oil & $11.2 \pm 0.6$ & $15.3 \pm 0.4$ & $15.9 \pm 0.3$ \\
\hline Physical properties & $73 \pm 20$ & $280 \pm 30$ & $340 \pm 15$ \\
\hline $\begin{array}{l}\text { Ultimate tensile strength } \\
\text { [MPa] }\end{array}$ & $89 \pm 1$ & $91 \pm 1$ & $83 \pm 3$ \\
\hline $\begin{array}{l}\text { Elongation at break } \\
{[\%]}\end{array}$ & $5.9 \pm 0.5$ & $3.2 \pm 0.5$ & $2.1 \pm 0.5$ \\
\hline $\begin{array}{l}\text { Compression set } \\
{[\%]}\end{array}$ & $28.2 \pm 0.5 \mathrm{a}$ & $14.8 \pm 0.5$ & $19.6 \pm 0.5$ \\
\hline $\begin{array}{l}\text { Tension set } \\
\text { (at 50\% deformation) [\%] }\end{array}$ & $8.1 \pm 0.5$ & $6.5 \pm 0.2$ & $5.8 \pm 0.4$ \\
\hline $\begin{array}{l}\text { Tension set } \\
\text { (at 100\% deformation) [\%] }\end{array}$ & \begin{tabular}{l}
$\mid l$ \\
\hline $\begin{array}{l}\text { Swelling in ASTM \#3 oil } \\
{[\%]}\end{array}$
\end{tabular} &
\end{tabular}

$\mathrm{NV}=$ non vulcanized blends

atension set at break 
at break lower than $100 \%$. These results indicate good elastomeric properties, promoted by a reduced interfacial tension between the phases and by a stable dispersion of the rubber particles.

\subsection{The effect of dynamic vulcanization}

As extensively reviewed in the literature, the best way to produce thermoplastic elastomer blends containing finely dispersed rubber phase is through the dynamic vulcanization. Table 2 presents the main physical and tensile properties of the dynamically vulcanized PP/ACM blends. The reactive compatibilization was also effective in dynamically vulcanized blends, when it was observed a significant increase of tensile properties. This behavior may be attributed to a decrease of the interfacial tension promoted by the compatibilization, resulting in rubber domains with smaller particle size, which can be completely encapsulated by the less viscous PP component.

The compatibilization also improved the tensile set of vulcanized blends. As observed in Table 2, the compatibilized blends presented good tension set behavior (lower values) for experiments performed at 50 or $100 \%$ of deformation. The non compatibilized blends presented higher values or, in the case of $100 \%$ of elongation, the specimens broke during the experiment and could not be tested.

Table 2. Physical and mechanical properties of vulcanized PP/ACM blends

\begin{tabular}{|l|c|c|}
\hline \multicolumn{1}{|c|}{ Ingredients (by weight) } & V1 & V2 \\
\hline PP & 50 & 50 \\
\hline ACM & 50 & 50 \\
\hline PPg-MA & 0 & 5 \\
\hline TETA & 0 & 0.2 \\
\hline Stearic acid & 1 & 1 \\
\hline WB-222 & 1.5 & 1.5 \\
\hline Sodium stearate & 1.5 & 1.0 \\
\hline Chemac Park 50 & $11.0 \pm 0.6$ & $16.5 \pm 0.2$ \\
\hline Physical properties & $50 \pm 5$ & $190 \pm 4$ \\
\hline Ultimate tensile strength [MPa] & $89 \pm 1$ & $82 \pm 2$ \\
\hline Elongation at break [\%] & $9.3 \pm 0.5$ & $6.3 \pm 0.5$ \\
\hline Compression set [\%] & - & $24.6 \pm 0.5$ \\
\hline Tension set (at 50\% elongation) [\%] & $4.6 \pm 0.5$ & $4.2 \pm 0.2$ \\
\hline Tension set (at 100\% elongation) [\%] & \multicolumn{2}{|c|}{} \\
\hline Swelling in ASTM \#3 oil [\%] &
\end{tabular}

\subsection{Morphology}

The mechanical properties, especially elongation at break and tension set, were superior in non vulcanized blends, and can be explained by the morphology of the rubber dispersed phase. Figure 6 compares the SEM micrographs of PP/ACM (50:50 parts) blends as a function of the compatibilization and vulcanization. The white region corresponds to the rubber phase, which was selectively stained by $\mathrm{RuO}_{4}$. Non vulcanized and non compatibilized blend presented a co-continuous structure, with large rubber phase because of the incompatibility between the phases. The compatibilization promoted a phase inversion with the rubber particle uniformly distributed inside the PP matrix (Figure 6b). This morphology is in agreement with the outstanding mechanical performance observed for this blend. Contrarily to the usual behavior of dynamic vulcanized blends, the vulcanization of PP/ACM blends resulted in a gross phase separated morphology. The non compatibilized blend presented very large rubber particle domains, as observed in Figure 6c. The reactive compatibilization improved the morphology, resulting in smaller crosslinked rubber particles, well dispersed inside the PP matrix (Figure 6d). However, this compatibilized blend still presents gross phase separated morphology, as compared to the non vulcanized blend (Figure 6b).

The curing process of the ACM rubber phase performed by Chemac Park 50 (a hexamethylene diamine carbamate) is believed to involve the reaction between hexamethylene diamine (generated from the decomposition of Chemac Park 50 at high processing temperature) and chloride and/or carboxylic groups of ACM, according to the scheme proposed in Figure 7. The curing system was added 3 min after the addition of the processing aid systems. Therefore, it is believed that the curing process started to occur before the rubber domains have enough time to deform and break up into smaller particles. Consequently, larger vulcanized domains of rubber were obtained. The compatibilization decreases the interfacial tension and avoids coalescence until the addition of the curing agent, contributing for the formation of smaller rubber particle size, and consequently an improvement of the mechanical performance.

Regarding the compatibilized, but non vulcanized blends, after the introduction of TETA and the pro- 


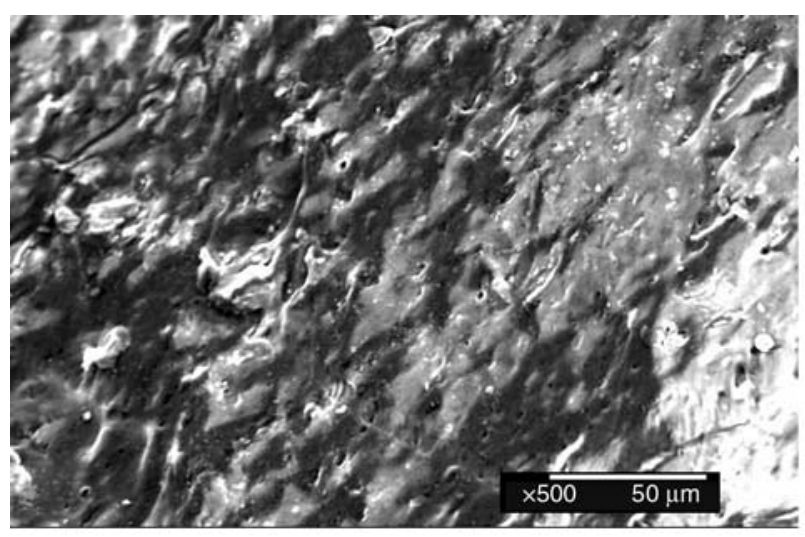

a)

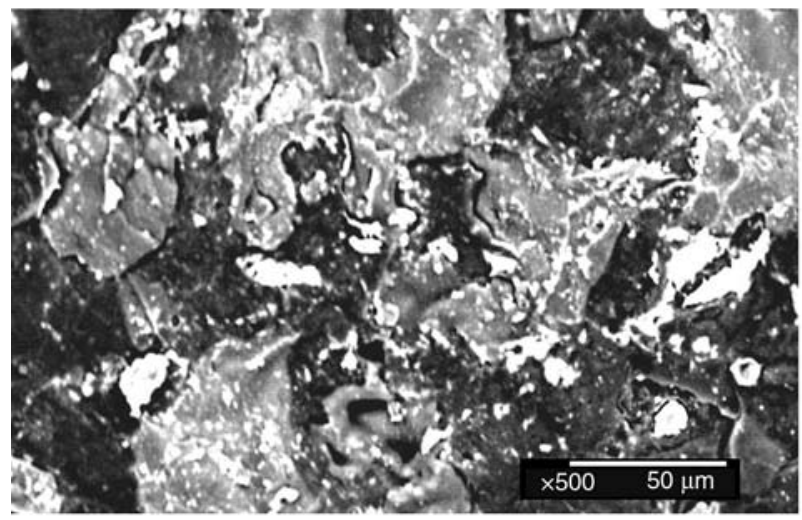

c)

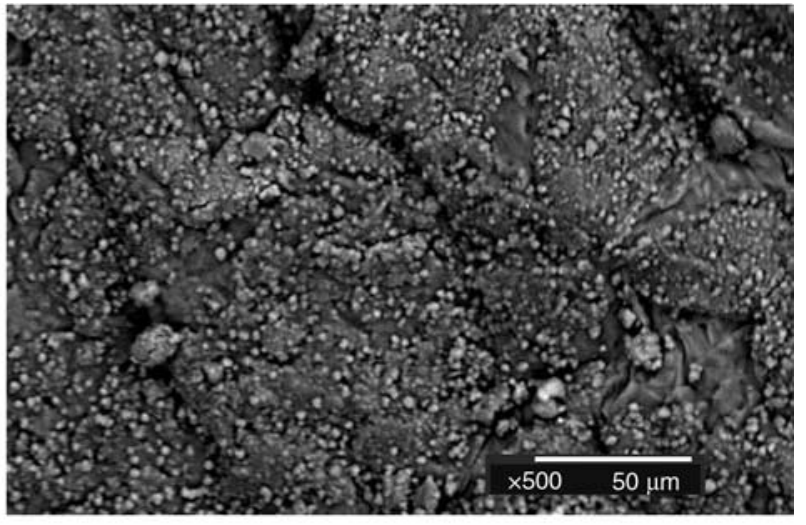

b)

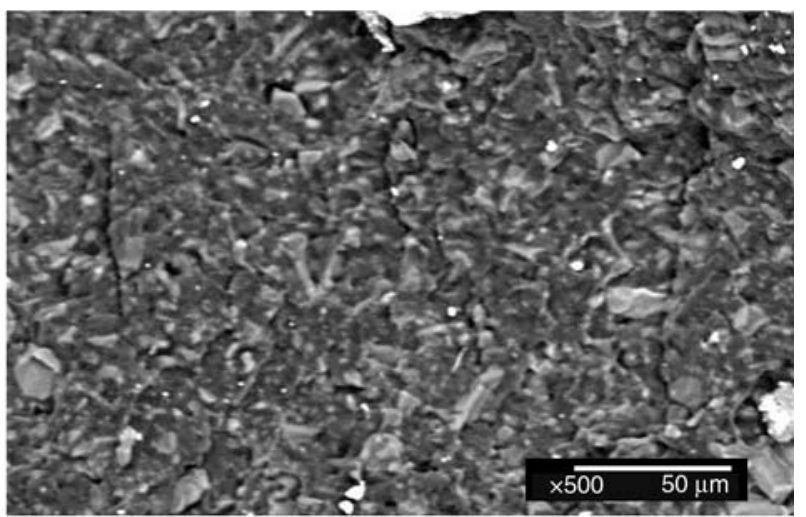

d)

Figure 6. SEM micrographs of PP/ACM (50:50 parts) blends: (a) non vulcanized/non compatibilized; (b) non vulcanized/ compatibilized with PP-g-MA/TETA (5:0.5); (c) vulcanized/non compatibilized; (d) vulcanized/compatibilized with PP-g-MA/TETA $(5: 0.5)$

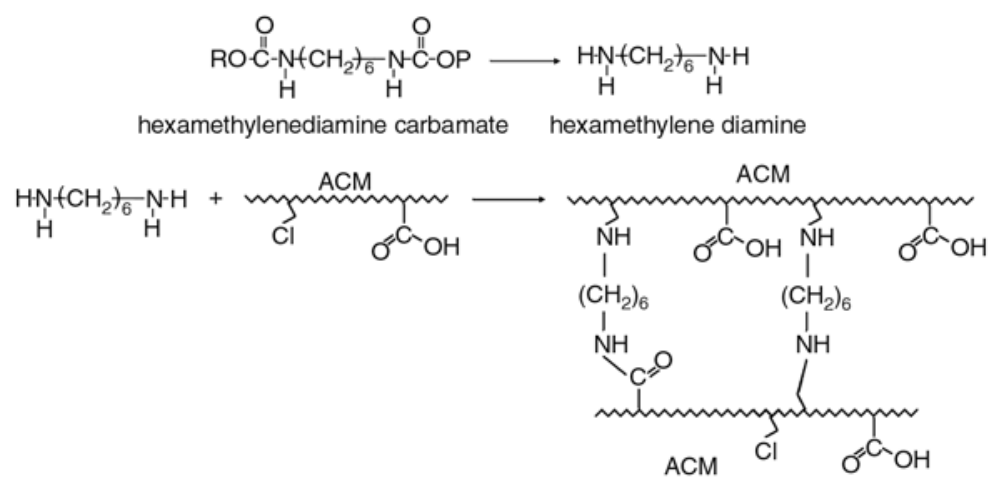

Figure 7. Proposal of the curing mechanism of ACM phase by hexamethylene diamine carbamate

cessing aid, this blend was processed for additional $7 \mathrm{~min}$, which imparts the break up of the droplets in higher extent and a more effective dispersion of the rubber particle inside the PP matrix. In addition, TETA is a diamine compound (similarly to the decomposed form of Chemac Park 50) and may also react with the functional groups of the ACM phase, introducing some crosslinking into this phase. Therefore, the presence of TETA promoted a decrease of the interfacial tension, an improve- ment of the interfacial adhesion and the crosslinking of the rubber particles. All these features contribute for an improved morphology and the outstanding elastomeric properties of this blend.

\subsection{Stress relaxation experiments}

The improvement of the elastomeric characteristics of PP/ACM blends with the compatibilization was also observed from stress relaxation experiments 


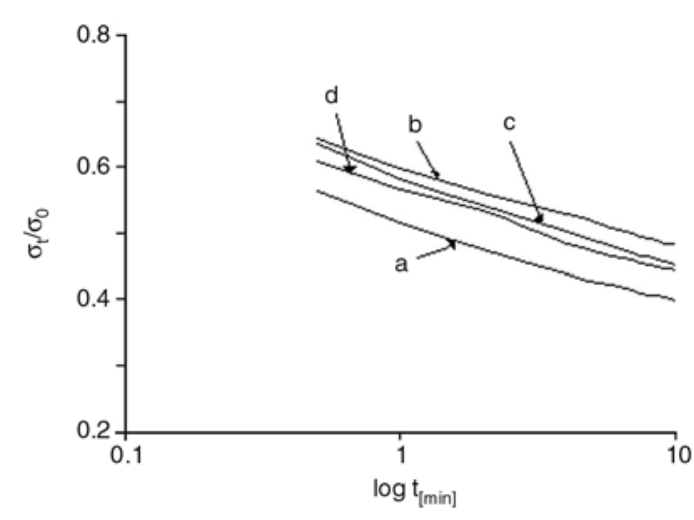

Figure 8. $\left(\sigma_{t} / \sigma_{0}\right)$ versus $\log t$ plots of non vulcanized and vulcanized PP/ACM (50:50 parts) blends at a strain level of $100 \%$ (a) non vulcanized/non compatibilized blend; non vulcanized/compatibilized blend with (b) PP-g-MA/TETA (5:02);

(c) PP-g-MA/TETA (5:0.5); (d) vulcanized and compatibilized with PP-g-MA/TETA (5:0.5)

carried out at $25^{\circ} \mathrm{C}$. Figure 8 illustrates the $\left(\sigma_{t} / \sigma_{0}\right)$ versus time plots for non vulcanized and vulcanized ACM/PP blends at $100 \%$ strain, where $\sigma_{t}$ is the stress at time $t$ and $\sigma_{0}$ is the stress at $t=0$. In all blends, the experimental points fell on a single straight line, indicating that the relaxation process involves a single mechanism [24]. For non vulcanized blends the compatibilization resulted in slightly lower stress relaxation (lower stress decay). In addition the value of $\left(\sigma_{t} / \sigma_{0}\right)$ for the same time is

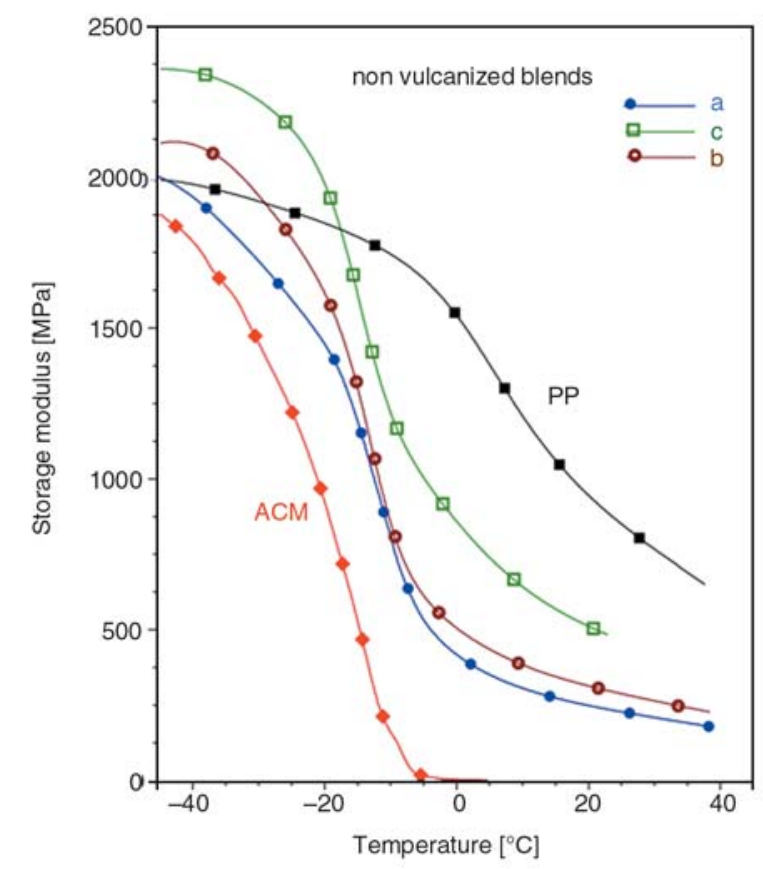

higher for compatibilized and non vulcanized blends, indicating an increasing of the elastic property of these blends because of the effective entanglement of the chains at the interface. The dynamic vulcanization resulted in a little higher stress relaxation (curve d). The best elastic response was observed for compatibilized/non vulcanized PP/ ACM blends. This behavior confirms the good interfacial adhesion between the ACM and PP phases promoted by the PP-g-MA in combination with TETA as the coupling agent, and the crosslinking of the rubber particles.

\subsection{Dynamic mechanical analysis}

The dynamic mechanical properties such as storage modulus $\left(E^{\prime}\right)$ and damping $(\tan \delta)$ of the PP/ACM blends were evaluated from -60 to $+60^{\circ} \mathrm{C}$. Figure 9 illustrates the variation of the storage modulus $\left(E^{\prime}\right)$ with the temperature for non vulcanized and dynamically vulcanized PP/ACM (50:50 parts) blends, as a function of the compatibilization. In both vulcanized and non vulcanized blends, those containing the compatibilizing system displayed the highest storage modulus over the entire temperature range. In non vulcanized blends, the increase in TETA content resulted in a substantial increase of modulus (curve c). These results are in agree-

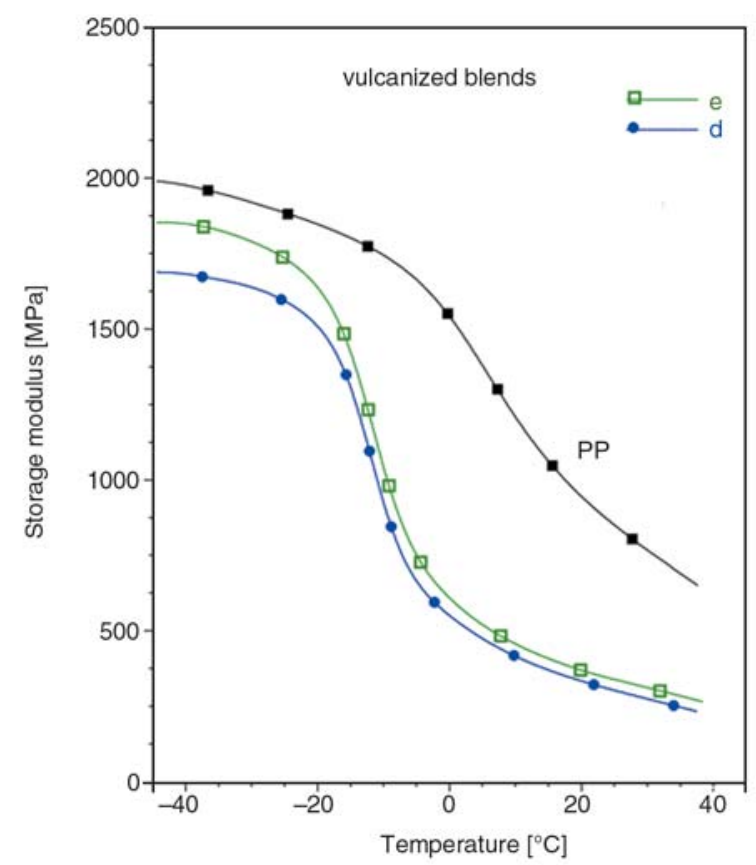

Figure 9. Dependence of storage modulus $\left(E^{\prime}\right)$ with the temperature for PP/ACM (50:50 parts) blends: (a) non vulcanized/non compatibilized blend; non vulcanized/compatibilized blend with PP-g-MA/TETA (b) (5:0.2 parts) and (c) (5:0.5 parts); (d) vulcanized/non compatibilized blend; (e) vulcanized/compatibilized blend with PP-g-MA/ TETA (5:0.5). 
Table 3. DMA and DSC results of PP/ACM (50:50 parts) blends as a function of the compatibilization

\begin{tabular}{|c|c|c|c|c|c|c|c|c|}
\hline \multicolumn{2}{|c|}{ Compatibilizing system [wt\%] } & \multicolumn{4}{|c|}{ DMA results } & \multicolumn{3}{|c|}{ DSC results } \\
\hline PP-g-MA & TETA & $\tan \delta$ & $\mathbf{T}_{\mathrm{g}}\left[{ }^{\circ} \mathbf{C}\right]$ & $\mathrm{E}^{\prime}\left(-40^{\circ} \mathrm{C}\right)[\mathrm{MPa}]$ & $\mathbf{E}^{\prime}\left(\mathbf{2 0}^{\circ} \mathrm{C}\right)[\mathrm{MPa}]$ & $\mathbf{T}_{\mathrm{m}}\left[{ }^{\circ} \mathbf{C}\right]$ & $\Delta \mathbf{H}[\mathbf{J} / \mathrm{g}]$ & $\mathbf{T}_{\mathbf{c}}\left[{ }^{\circ} \mathbf{C}\right]$ \\
\hline \multicolumn{9}{|c|}{ Non vulcanized blends } \\
\hline 0 & 0 & 0.31 & -8.4 & 1930 & 230 & 159.8 & 36.0 & 113 \\
\hline 5 & 0.2 & 0.26 & -10.3 & 2100 & 290 & 161.1 & 37.5 & 120 \\
\hline 5 & 0.5 & 0.16 & -12.7 & 2350 & 490 & 161.3 & 38.6 & 120 \\
\hline \multicolumn{9}{|c|}{ Vulcanized blends } \\
\hline 0 & 0 & 0.27 & -9.3 & 1680 & 300 & 161.0 & 37.8 & 114 \\
\hline 5 & 0.5 & 0.21 & -10 & 1850 & 380 & 165.0 & 40.6 & 120 \\
\hline
\end{tabular}
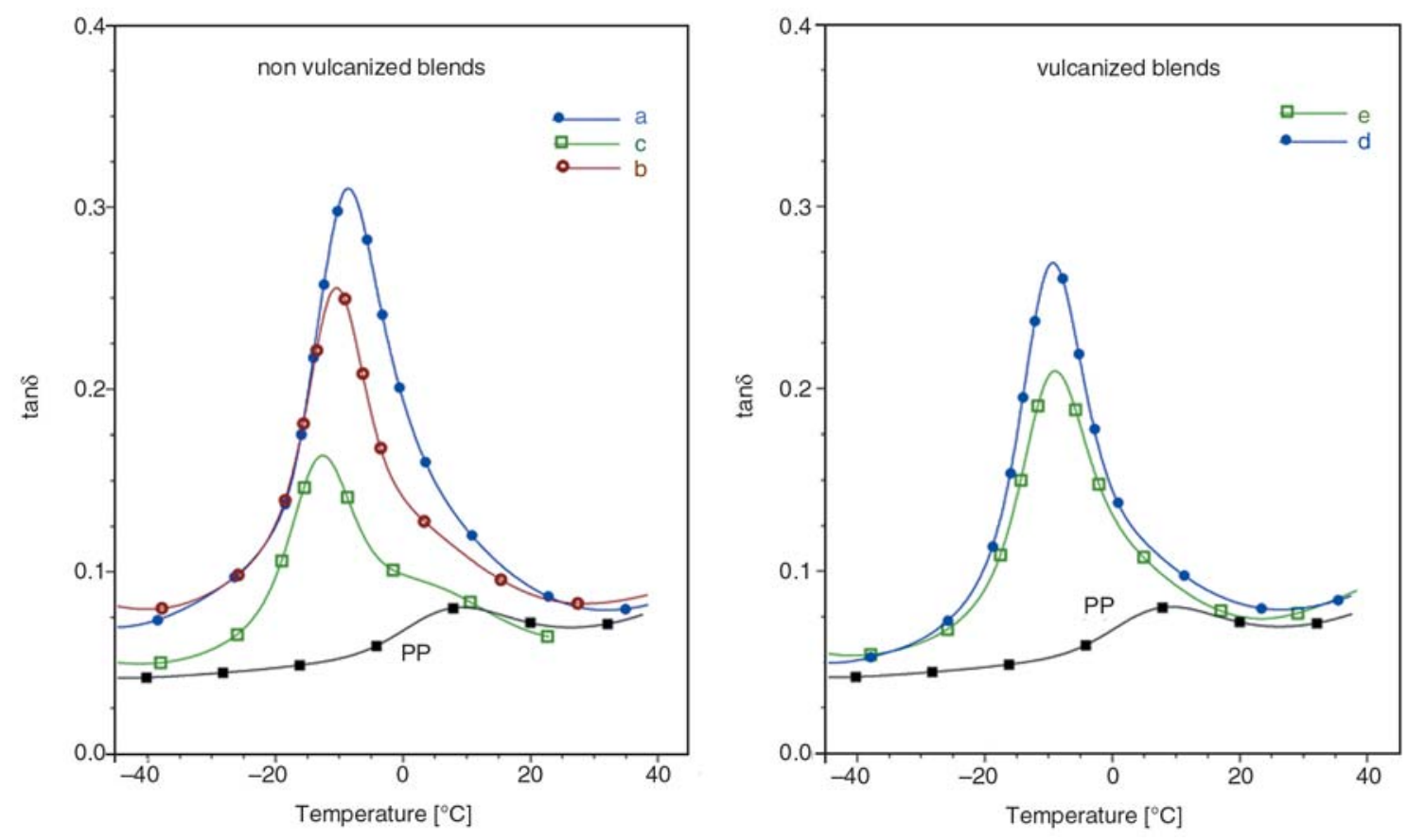

Figure 10. Dependence of $\tan \delta$ with the temperature for PP/ACM (50:50 parts) blends: (a) non vulcanized/non compatibilized blend; non vulcanized/compatibilized blend with PP-g-MA/TETA (b) (5:0.2parts) and (c) (5:0.5parts);

(d) vulcanized/non compatibilized blend; (e) vulcanized/compatibilized blend with PP-g-MA/TETA (5:0.5)

ment with the mechanical performance and confirm the interfacial adhesion caused by the emulsifying effect of the network formed at the interface, as a consequence of the reactive compatibilization. These interactions increase the stiffness of the material and reflect on the increase of modulus of the blends at room temperature. The values of modulus and other dynamic mechanical parameters are also summarized in Table 3.

The dependence of $\tan \delta$ with the temperature for PP/ACM blends is illustrated in Figure 10. The main relaxation at around $-10^{\circ} \mathrm{C}$ is related to the glass-rubber transition of the ACM phase. The relaxation due to the PP phase appears at around $10-15^{\circ} \mathrm{C}$, but it is only detected as a small shoulder at this temperature region because of its very low damping when compared to the ACM. The compatibilized blends presented a decrease of damping $(\tan \delta)$ due to the decrease of the chain mobility as a result of the interfacial adhesion. Comparing the vulcanized and non vulcanized blends with the same composition, the vulcanized but non compatibilized blend displayed lower $\tan \delta$, due to the mobilization restriction imparted by the crosslinks. However, for compatibilized blends lower $\tan \delta$ and higher $E^{\prime}$ values were observed in non vulcanized blend. This behavior suggests that the compatibilizing system imparts some crosslinking to the rubber phase, and the posterior vulcanization may result an overcuring process and degradation of the blend, which decreases the crosslinking density of this blend. This behavior explains the inferior mechanical properties of the vulcanized blends when compared to the non vulcanized ones.

The glass transition temperature (established as the temperature corresponding to the maximum of the 
$\tan \delta$ peak) presented a slight decrease with the compatibilization, for non vulcanized blends. However, for vulcanized blends, the compatibilization did not exert influence on the transition temperature.

\subsection{DSC analysis}

The effect of the compatibilization and the dynamic vulcanization on the thermal behavior of PP/ACM (50:50 parts) blends was studied by differential scanning calorimetry, whose main results are summarized in Table 3. The addition of the compatibilizing agent increased both $T_{m}$ and $T_{c}$ of the PP phase, but the effect was more pronounced in the $T_{c}$ values. Also the melt enthalpy presented a little increasing with the compatibilization. These results suggest that the compatibilization restricts the movement of the macromolecular chain because of the enhanced interaction between the phases, resulting in higher $T_{m}$ values. In addition, the compatibilizing agent acts as a nucleating agent increasing the melt enthalpy.

\subsection{Effect or reprocessing}

An important advantage of TPVs over conventional thermosetting rubbers is that they can be reprocessed by all common equipment for plastic processing, without significant changes in physical properties. The reprocessability was tested in compatibilized blends (non vulcanized and vulcanized blends). The blends were studied after three cycles of injection molding, with the product being reground after each molding cycle. The tensile properties were measured after each cycle, and the results are summarized in Table 4 . Both non vulcanized and vulcanized blends presented an increase of ultimate tensile strength after the first cycle, indicating additional interactions and/or crosslinking taking place at this stage. After the second and third cycles, the tensile strength decreased, but the values still remained higher than the original values. The elongation at break decreased after the first cycle for non vulcanized blend. However, for vulcanized blend, it was observed an increase of this value with reprocessing. These results indicate that these blends can be considered a reprocessable thermoplastic elastomer.

\section{Conclusions}

Thermoplastic elastomers based on polypropylene and acrylic rubber were studied for the first time, with special emphasis on the effect of the reactive compatibilization and dynamic vulcanization. The compatibilization with maleic anhydride-functionalized PP/TETA system resulted in a significant improvement of mechanical properties and oil resistance. In addition it was observed a significant improvement on the elasticity of the material as indicated by the lower tension set values and a lower stress relaxation. The reactive compatibilization was also suggested by the increase of the torque during mixing and by the increase of the viscosity and storage modulus of the blends.

The dynamic vulcanization process was only effective for compatibilized blends. For this blend, the vulcanized rubber particles presented lower particle size, which was effectively surrounded by the PP matrix, characterizing an actual thermoplastic vulcanizate. However, superior mechanical performance and finer morphology with smaller rubber particle size were achieved for non vulcanized/ compatibilized blends. Probably due to the decrease of the interfacial tension, the improvement of the interfacial adhesion and the crosslinking of the rubber particles, imparted by TETA in combination with PP-g-MA.

The reactive compatibilization also resulted in a decrease of damping and an increase of storage modulus obtained from dynamic mechanical analysis and an increase of melting and crystallization

Table 4. Tensile properties of compatibilized PP/ACM blends as a function of the reprocessing

\begin{tabular}{|c|c|c|c|c|}
\hline \multirow{3}{*}{ Cycles } & \multicolumn{2}{|c|}{ Non vulcanized blend (NV2) } & \multicolumn{2}{c|}{ Vulcanized blend (V2) } \\
\cline { 2 - 5 } & $\begin{array}{c}\text { Ultimate tensile strength } \\
{[\mathbf{M P a}]}\end{array}$ & $\begin{array}{c}\text { Elongation at break } \\
{[\%]}\end{array}$ & $\begin{array}{c}\text { Ultimate tensile strength } \\
{[\mathbf{M P a}]}\end{array}$ & $\begin{array}{c}\text { Elongation at break } \\
{[\%]}\end{array}$ \\
\hline 1 & $15.3 \pm 0.4$ & $280 \pm 30$ & $16.5 \pm 0.2$ & $190 \pm 4$ \\
\hline 2 & $17.7 \pm 0.3$ & $230 \pm 20$ & $17.7 \pm 0.3$ & $200 \pm 10$ \\
\hline 3 & $16.4 \pm 0.1$ & $235 \pm 35$ & $17.1 \pm 0.2$ & $190 \pm 8$ \\
\hline 4 & $16.3 \pm 0.2$ & $310 \pm 25$ & $16.6 \pm 0.4$ & $220 \pm 15$ \\
\hline
\end{tabular}


temperature as a result of the mobilization restriction imparted by the chemical bonds at the interface. The PP/ACM thermoplastic elastomers presented good reprocessing ability.

\section{Acknowledgements}

We would like to acknowledge the Conselho Nacional de Desenvolvimento Científico e Tecnológico (CNPq), Coordenação de Aperfeiçoamento de Pessoal de Nivel Superior (CAPES), Financiadora de Estudos e Projetos (FINEP), Fundação de Amparo à Pesquisa do Estado do Rio de Janeiro (FAPERJ) and Petroflex Ind. Com. S.A. (now Lanxess) for the financial support for this project.

\section{References}

[1] Nakajima N., DeMarco R. D.: Application of polyacrylate rubber for high performance automotive gaskets and seals. Journal of Elastomers and Plastics, 33, 114-120 (2001).

[2] Vial T. M.: Recent developments in acrylic elastomers. Rubber Chemistry and Technology, 44, 344362 (1971).

[3] Giannetti E., Mazzocchi R., Fiore L., Crespi E.: Ammonium salt catalyzed crosslinking mechanism of acrylic rubbers. Rubber Chemistry and Technology, 56, 21-30 (1983).

[4] Jha A., Dutta B., Bhowmick A. K.: Effect of fillers and plasticizers on the performance of novel heat and oil-resistant thermoplastic elastomers from nylon-6 and acrylate rubber blends. Journal of Applied Polymer Science, 74, 1490-1501 (1999).

[5] Jha A., Bhowmick A. K.: Thermal degradation and ageing behavior of novel thermoplastic elastomeric nylon-6/acrylate rubber reactive blends. Polymer Degradation and Stability, 62, 575-586 (1998).

[6] Ding X., Xu R., Yu D., Chen H., Fan R.: Effect of ultrafine, fully vulcanized acrylate powdered rubber on the mechanical properties and crystallization behavior of nylon 6. Journal of Applied Polymer Science, 90, 3503-3511 (2003).

[7] Jha A., Bhowmick A. K.: Influence of dynamic vulcanization and phase interaction on the swelling behavior of the thermoplastic elastomeric blends of nylon- 6 and acrylate rubber in various solvents and oil. Journal of Applied Polymer Science, 69, 23312340 (1998).

[8] Wong-On J., Wootthikanokkhan J.: Dynamic vulcanization of acrylic rubber-blended PVC. Journal of Applied Polymer Science, 88, 2657-2663 (2003).

[9] Wimolmala E., Wootthikanokkhan J., Sombatsompop N.: Effects of composition and temperature on extrudate characteristics, morphology, and tensile properties of acrylic rubber-blended PVC. Journal of Applied Polymer Science, 80, 2523-2534 (2001).
[10] Li Y., Yuko O., Kadowaki Y., Inoue T., Nakayama K., Shimizu H.: A novel thermoplastic elastomer by reaction-induced phase decomposition from a miscible polymer blend. Macromolecules, 39, 4195-4201 (2006).

[11] Shivakumar E., Srivastava R. B., Pandey K. N., Das C. K.: Compatibility study of blends of acrylic rubber (ACM), poly(ethyleneterephtalate) (PET), and liquid crystalline polymer (LCP). Journal of Macromolecular Science, Part A: Pure and Applied Chemistry, 42, 1181-1195 (2005).

[12] Wu C., Otani Y., Namiki N., Emi H., Nitta K-H.: Phase modification of acrylate rubber/chlorinated polypropylene blends by a hindered phenol compound. Polymer Journal, 33, 322-329 (2001).

[13] Margolis J. M.: Elastomeric materials and processes. in 'Handbook of Plastics, Elastomers and Composites' (ed.: Harper C. A.) McGraw-Hill, New York, 189 228 (2004).

[14] Gupta N. K., Jain A. K., Singhal R., Nagpal A. K.: Effect of dynamic crosslinking on tensile yield behavior of polypropylene/ethylene-propylene-diene rubber blends. Journal of Applied Polymer Science, 78, 2104-2121 (2000).

[15] Chatterjee K., Naskar K.: Development of thermoplastic elastomers based on maleated ethylene propylene rubber (m-EPM) and polypropylene (PP) by dynamic vulcanization. Express Polymer Letters, 1, 527-534 (2007).

[16] Manchado M. A. L., Arroyo M., Kenny J. M: New developments in dynamically cured PP-EPDM blends. Rubber Chemistry and Technology, 74, 211-220 (2002).

[17] Zhang X., Huang H., Zhang Y.: Dynamically vulcanized nitrile rubber/polypropylene thermoplastic elastomers. Journal of Applied Polymer Science, 85, 2862-2866 (2002).

[18] Naderi G., Nouri M. R., Mehrabzadeh M., Bakhshandeh G. R.: Studies on dynamic vulcanization of PP/NBR thermoplastic elastomer blends. Iranian Polymer Journal, 8, 37-42 (1999).

[19] George S., Varughese K. T., Thomas S.: Dielectric properties of isotactic polypropylene/nitrile rubber blends: Effects of blend ratio, filler addition, and dynamic vulcanization. Journal of Applied Polymer Science, 73, 255-270 (1999).

[20] Coran A. Y., Patel R.: Rubber-thermoplastic compositions. VIII. Nitrile rubber-polyolefin blends with technological compatibilization. Rubber Chemistry and Technology, 56, 1045-1060 (1983).

[21] Soares B. G., Almeida M. S. M., Deepa Urs M. V., Kumaraswamy G. N., Ranganathaiah C., Siddaramaiah, Mauler R.: Influence of curing agent and compatibilizer on the physicomechanical properties of polypropylene/nitrile butadiene rubber blends investigated by positron annihilation lifetime technique. Journal of Applied Polymer Science, 102, 4672-4681 (2006). 
[22] Nakason C., Wannavilai P., Kaesaman A.: Thermoplastic vulcanizates based on epoxidized natural rubber/polypropylene blends: Effect of epoxide levels in ENR molecules. Journal of Applied Polymer Science, 101, 3046-3052 (2006).

[23] Thitihammawong A., Nakason C., Sahakaro K., Noordermeer J.: Effect of different types of peroxides on rheological, mechanical and morphological properties of thermoplastic vulcanizates based on natural rubber/polypropylene blends. Polymer Testing, 26, 537546 (2007).
[24] Asaletha R., Bindu P., Aravind I., Meera A. P., Valsaraj S. V., Yang W., Thomas S.: Stress-relaxation behavior of natural rubber/polystyrene and natural rubber/polystyrene/natural rubber-graft-polystyrene blends. Journal of Applied Polymer Science, 108, 904-913 (2008). 